\title{
Heat, Hydration and the Human Brain, Heart and Skeletal Muscles
}

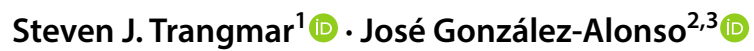

Published online: 22 January 2019

(c) The Author(s) 2019

\begin{abstract}
People undertaking prolonged vigorous exercise experience substantial bodily fluid losses due to thermoregulatory sweating. If these fluid losses are not replaced, endurance capacity may be impaired in association with a myriad of alterations in physiological function, including hyperthermia, hyperventilation, cardiovascular strain with reductions in brain, skeletal muscle and skin blood perfusion, greater reliance on muscle glycogen and cellular metabolism, alterations in neural activity and, in some conditions, compromised muscle metabolism and aerobic capacity. The physiological strain accompanying progressive exercise-induced dehydration to a level of $\sim 4 \%$ of body mass loss can be attenuated or even prevented by: (1) ingesting fluids during exercise, (2) exercising in cold environments, and/or (3) working at intensities that require a small fraction of the overall body functional capacity. The impact of dehydration upon physiological function therefore depends on the functional demand evoked by exercise and environmental stress, as cardiac output, limb blood perfusion and muscle metabolism are stable or increase during small muscle mass exercise or resting conditions, but are impaired during wholebody moderate to intense exercise. Progressive dehydration is also associated with an accelerated drop in perfusion and oxygen supply to the human brain during submaximal and maximal endurance exercise. Yet their consequences on aerobic metabolism are greater in the exercising muscles because of the much smaller functional oxygen extraction reserve. This review describes how dehydration differentially impacts physiological function during exercise requiring low compared to high functional demand, with an emphasis on the responses of the human brain, heart and skeletal muscles.
\end{abstract}

José González-Alonso

j.gonzalez-alonso@brunel.ac.uk

1 Department of Life Sciences, University of Roehampton, London, UK

2 Centre for Human Performance, Exercise and Rehabilitation, College of Health and Life Sciences, Brunel University London, Uxbridge UB8 3PH, UK

3 Division of Sport, Health and Exercise Sciences, Department of Life Sciences, College of Health and Life Sciences, Brunel University London, Uxbridge, UK

\section{Key Points}

Dehydration, the process of losing body water through thermoregulatory sweating, can lead to marked alterations in physiological function and decrements in endurance performance during training and competition in temperate and hot environments.

Impaired endurance capacity in the dehydrated and hyperthermic athlete is associated with physiological strain in multiple systems, organs and tissues involving the brain, heart and skeletal muscles.

Ingesting fluids during prolonged exercise in temperate and hot environments attenuates or even prevents the deleterious effects of dehydration on physiological function and endurance performance. 


\section{Introduction}

Dehydration and hyperthermia, which are frequently experienced by humans exercising in hot environments, are major physiological stressors that can severely hinder general physiological function and cognitive and athletic performance during endurance events (i.e., long distance running, cycling or swimming, triathlon and team sports) [1-8]. The interaction among the type, duration and intensity of exercise and the environmental conditions determines the body's overall functional demand. Dehydration poses additional stress on the human body regulatory systems, and its interaction with the overall functional demand will dictate the extent of the physiological and perceptual strain and thus whether physical performance is compromised. The endurance athlete's training and heat acclimation status would also have an influence. In this light, the severely dehydrated, heat unacclimated and unfit endurance athlete, who is training or competing in a hot and humid environment, will likely experience the most deleterious physiological and performance effects $[9,10]$. The mildly dehydrated, highly fit endurance athlete who is training and competing in a cold environment will be at the opposing end of the spectrum $[10,11]$.

This review considers how human physiological function is affected by exposure to heat and dehydration at rest, and during exercise of different modalities and intensities, with an emphasis on the blood perfusion and metabolism of regional tissues of the human body. The impact of dehydration and hyperthermia on physiological function will be interpreted primarily according to Ohm's law and the Fick principle, which have blood flow as a common denominator. Ohm's law is a fundamental law of physics that explains the physical factors that govern blood flow. When applied to the human cardiovascular system, Ohm's law states that (driving or perfusion) pressure equals flow times resistance, with pressure being the force that drives flow and resistance the force that opposes flow. The Fick principle, in turn, determines the rate of oxygen consumption by the human body, an organ, limb or tissue. This is equal to the product of blood flow and the arterial-venous oxygen content differences. Both Ohm's law and the Fick principle can be applied systemically to the cardiovascular system as a whole and/or regionally to, for instance, the exercising limbs, heart or brain, which are essential tissues and organs in the exercising human.

A major focus of the review is on examining the relationship between regional circulation and metabolism to evaluate whether reduced oxygen and nutrient supply to and aerobic metabolism by the human brain, heart and/or active skeletal muscle could explain the accelerated fatigue and impaired (whole-body) exercise capacity often seen in the significantly dehydrated and hyperthermic human. In this review whole-body exercise is defined as exercise that engages a large muscle mass such as cycling, running, rowing or swimming. Interested readers are directed to other topical reviews on the effects of dehydration on exercise performance $[7,12]$ and the interaction of possible factors contributing to fatigue during exercise in the heat [13].

\section{Heat, Hydration and Athletic Performance}

In this section, we discuss how ambient temperature and hydration interact to influence submaximal and maximal endurance performance and aerobic capacity. The underlying physiological mechanisms are explored in different body systems in subsequent sections.

\subsection{Heat, Hydration and Submaximal Endurance Performance}

Physical work capacity and endurance exercise performance are typically impaired in high ambient temperatures, particularly when accompanied by whole-body hyperthermia [4, 10, 14-19]. Galloway and Maughan, for instance, observed a $~ 45 \%$ decline in time to exhaustion when ambient air temperature was increased from 11 to $31^{\circ} \mathrm{C}$ [15], a finding in agreement with other studies in the literature $[15,16$, 20]. Submaximal endurance performance can be markedly degraded in the heat even with only a modest increase in core temperature [18, 21-23], suggesting a potential role of skin hyperthermia in the fatigue process. Dehydration, a natural consequence of body water losses through sweating, can compound the impairment in physical performance, but its impact is minimal when environmental temperature is low. In support of this idea, Kenefick and colleagues found that dehydration of $4 \%$ body mass reduced cycling time trial performance by up to $23 \%$ in a hot environment $\left(40{ }^{\circ} \mathrm{C}\right.$; no fan cooling), but the performance decrement was diminished to $12 \%, 5 \%$ and $3 \%$ when the ambient temperature was decreased to $30{ }^{\circ} \mathrm{C}, 20^{\circ} \mathrm{C}$ and $10{ }^{\circ} \mathrm{C}$, respectively [10]. The greater impact of dehydration on submaximal endurance performance in high compared to low ambient temperature is generally reflected in the available literature, where endurance performance shows little or no decrease in cooler conditions $[10,11]$ compared to much hotter and uncompensable environments [9, 24, 25] (see [12] for review). Interestingly, whole-body aerobic metabolism $\left(\dot{V} \mathrm{O}_{2}\right)$ remains at control levels during submaximal endurance exercise, despite evident physical performance degradation [26]. In addition, changes in substrate utilisation do not appear to impair aerobic exercise performance (e.g. time trial) [31] even though progressive dehydration [27-29] and 
hyperthermia [30] lead to enhanced carbohydrate oxidation and muscle glycogen utilisation.

\subsection{Heat, Hydration and Maximal Aerobic Capacity}

While submaximal endurance performance can be markedly impaired without significant reductions in whole-body $\dot{V} \mathrm{O}_{2}$, both maximal aerobic capacity $\left(\dot{V} \mathrm{O}_{2 \max }\right)$ and maximal endurance performance can be suppressed to a varied extent when performing in the very heavy and severe exercise intensity domains. Studies comprehensively exploring the independent and combined effects of body hyperthermia and dehydration on $\dot{V} \mathrm{O}_{2 \max }$ support this idea. In some cases heat stress only minimally reduces $\dot{V} \mathrm{O}_{2 \max }(\leq 3 \%)$ and endurance performance $[1,32]$, whereas in others, more substantial ( 7-30\%) impairments are shown [4, 5, 22, 33-38]. For example, Arngrimsson and colleagues found that $\dot{V} \mathrm{O}_{2 \max }$ was reduced by $\sim 4 \%, \sim 9 \%$ and $\sim 18 \%$ during constant-load treadmill running at $35{ }^{\circ} \mathrm{C}, 40{ }^{\circ} \mathrm{C}$ and $45^{\circ} \mathrm{C}$ ambient temperature, respectively. Of note, the fall in $\dot{V} \mathrm{O}_{2 \max }$ in the highest ambient temperature (i.e. $45^{\circ} \mathrm{C}$ ) was halved when the same exercise was performed without any preceding warm-up, suggesting that the combination of high internal (core) and skin temperature is an important prerequisite for a reduced maximal aerobic capacity. Their study, however, did not partition the effects on $\dot{V} \mathrm{O}_{2 \max }$ of skin hyperthermia and whole-body hyperthermia.

\subsection{Magnitude of the Circulatory Strain and Aerobic Performance}

To characterise the independent effect of skin hyperthermia in conditions requiring maximal aerobic capacity, a recent study carefully manipulated body temperature with a water-perfused suit to investigate the impact of high skin temperature without an increase in core temperature on $\dot{V} \mathrm{O}_{2 \max }$ and work capacity in endurance-trained cyclists [38]. In this study, participants performed three incremental exercise tests to volitional exhaustion with (1) skin hyperthermia $\left(T_{\mathrm{sk}}+6{ }^{\circ} \mathrm{C}\right)$, (2) whole-body hyperthermia $\left(T_{\mathrm{sk}}+6\right.$ and $T_{\text {core }}+1{ }^{\circ} \mathrm{C}$ ) or (3) control temperatures. Whole-body hyperthermia resulted in a similar average reduction in maximal work rate $(\sim 13 \%)$ and $\dot{V} \mathrm{O}_{2 \max }(\sim 8 \%)$ to that seen in the existing literature. Importantly, skin hyperthermia alone did not compromise work or aerobic capacity, with maximal work rate and $\dot{V} \mathrm{O}_{2 \max }$ attaining equivalent values to those seen during the control trial. In contrast to these recent findings, others have found a weak or non-existing relationship between the reduction in $\dot{V} \mathrm{O}_{2 \max }$ and high core temperature, fuelling support for the hypothesis that high skin blood flow requirements in the heat are a predominant factor reducing maximal aerobic capacity $[1,5,39]$. This theory is based on the evidence in untrained and unacclimated individuals that the impaired $\dot{V} \mathrm{O}_{2 \max }$ in the heat compared to a cool environment was associated with a $\sim 1.2 \mathrm{~L} \mathrm{~min}^{-1}$ lower maximal cardiac output $(\dot{Q})$ [1]. By extension, the lower maximal $\dot{Q}$ was purported to be related to substantial elevations in skin blood flow [5]. Two observations in trained individuals argue against the skin hyperthermia hypothesis: (1) skin hyperthermia does not seem to alter general physiological function (i.e., active tissue blood flow and metabolism) compared to control conditions [38], and (2) $\dot{V} \mathrm{O}_{2 \max }$ and maximal $\dot{Q}$ are not reduced below control levels [35]. Taken together, these observations indicate that, at least in trained participants, the extent of the rise in both internal and skin temperatures is an important prerequisite for the development of a considerable degree of physiological strain that results in a substantial decline in $\dot{V} \mathrm{O}_{2 \max }$ in hot conditions.

The magnitude of whole-body hyperthermia is also an important factor in determining whether dehydration augments cardiovascular strain (i.e., reduces peripheral and systemic blood flow and mean arterial pressure and increases peripheral vascular resistance), and ultimately compromises aerobic capacity. Dehydration does not compromise or induces only small reductions in $\dot{V} \mathrm{O}_{2 \max }$ and exercise performance in cool environments where humans experience much lower skin and core temperatures [40-42]. However, when dehydration is coupled with high ambient temperatures and therefore whole-body hyperthermia becomes apparent, $\dot{V} \mathrm{O}_{2 \max }$ and maximal endurance performance are compromised. For example, Ganio et al. [43] discovered $\dot{V} \mathrm{O}_{2 \max }$ to be reduced by $8.7 \%$ when participants were dehydrated by $3.7 \%$ following $120 \mathrm{~min}$ of submaximal cycling in the heat [43]. When the loss in body mass was minimised (e.g. by shortening the duration of submaximal exercise), or when fluid was regularly ingested, no significant fall in $\dot{V} \mathrm{O}_{2 \max }$ was observed. Therefore, it seems that to negatively affect $\dot{V} \mathrm{O}_{2 \max }$ and maximal endurance performance the degree of dehydration should be $\geq 3 \%$ body mass loss. A word of caution is needed here, as the physiological effects of dehydration interact with those of hyperthermia and thus the magnitude of both stressors should be considered in predicting their impact on $\dot{V} \mathrm{O}_{2 \max }$ and maximal endurance performance.

Figure 1 illustrates the $\dot{V} \mathrm{O}_{2}$ dynamics data during constant-load maximal aerobic exercise reported by Nybo and colleagues [34]. In this study, endurance-trained athletes performed four cycling bouts to exhaustion at $\sim 402 \mathrm{~W}$ in different hydration and thermal states. Hydration status was carefully manipulated during $2 \mathrm{~h}$ of prior submaximal cycling in the heat to evoke either $4 \%$ body mass loss and hyperthermia (dehydration and hyperthermia), or maintain hydration status and normal body temperatures by ingesting fluid during exercise (euhydration control). In addition, 


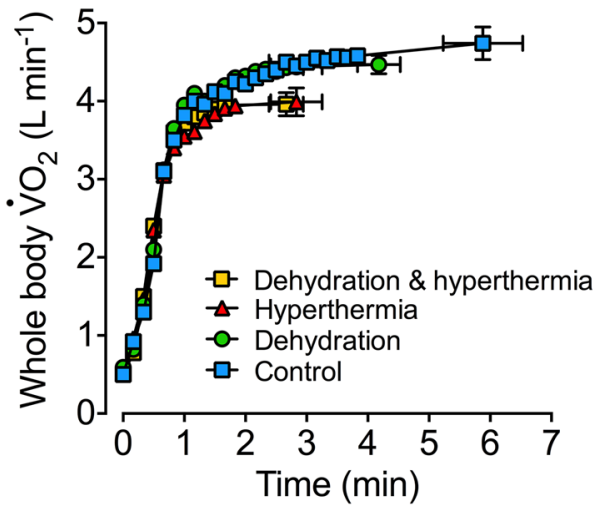

Fig. 1 Effects of dehydration and hyperthermia on aerobic capacity and maximal endurance capacity. Oxygen consumption dynamics were measured during constant load maximal cycling $(402 \pm 4 \mathrm{~W})$ under control, dehydration ( $4 \%$ body weight loss without hyperthermia), hyperthermia $\left(+1{ }^{\circ} \mathrm{C}\right.$ and $+6{ }^{\circ} \mathrm{C}$ increases in $T_{\text {es }}$ and $T_{\text {sk }}$, respectively) and combined dehydration and hyperthermia. Note that both combined dehydration and hyperthermia and hyperthermia alone impaired $\dot{V} \mathrm{O}_{2 \max }$ and exercise performance by $16 \%$ and $51-53 \%$ compared to control, without altering the initial absolute $\dot{V} \mathrm{O}_{2}$ responses. Preventing hyperthermia in dehydrated individuals restored $\dot{V} \mathrm{O}_{2 \max }$ and exercise performance by $65 \%$ and $50 \%$, respectively. These data demonstrate that aerobic metabolism and maximal endurance capacity can be drastically compromised in the dehydrated and hyperthermic human. Figure redrawn from data (means \pm SE) reported by Nybo et al. [34]. $T_{e s}$ oesophageal temperature, $T_{s k}$ mean skin temperature, $\dot{V} O_{2}$ oxygen uptake, $\dot{V} O_{2 \max }$ maximal aerobic capacity

thermal strain was manipulated with a water-perfused suit to induce low body temperatures during maximal exercise when dehydrated (dehydration alone) or skin and core hyperthermia when euhydrated (whole-body hyperthermia alone). The combination of dehydration and hyperthermia and whole-body hyperthermia alone reduced performance time by $\sim 52 \%$ and $\dot{V} \mathrm{O}_{2 \max }$ by $\sim 16 \%$ compared to the control hydrated condition (Fig. 1). When the athletes exercised in a dehydrated state, but with low body temperatures, the falls in maximal endurance capacity and $\dot{V} \mathrm{O}_{2 \max }$ were noticeably attenuated ( $\sim 25 \%$ and $\sim 6 \%$, respectively). A common finding of this and previous studies is that dehydration alone can reduce maximal exercise capacity without marked reductions in $\dot{V} \mathrm{O}_{2 \max }[34,40,41]$. The earlier fatigue when dehydrated, but 'normothermic', likely reflects the persistent reduction in blood volume, leading to compromised locomotor and systemic blood flow and oxygen delivery, as maximal heart rate is similar at exhaustion [34, 40, 41]. In conclusion, dehydration amounting to $3-4 \%$ body mass loss reduces physical work and endurance exercise capacity and augments the development of body hyperthermia, so that these two stressors in combination can in some conditions hinder $\dot{V} \mathrm{O}_{2 \max }$. Many of these studies, however, did not focus on the physiological mechanisms underpinning the reduced athletic performance. The following sections explore how dehydration and hyperthermia affect oxygen and the nutrient supply and metabolism of specific tissues of the human body and general physiological function.

\section{Heat, Hydration and the Heart}

Environmental conditions and hydration status are well known physiological stressors altering central haemodynamics during submaximal and maximal exercise. Exercise in heat in the euhydrated state increases heart rate and $\dot{Q}$ $\left(\geq 1 \mathrm{~L} \mathrm{~min}^{-1}\right)$ and is associated with a lower arterial pressure compared to exercise in the cold [17]. The effects of exercise-induced dehydration on central haemodynamics are also magnified in the heat [17]. Cardiac output and, to a lesser extent, arterial pressure decline with graded levels of dehydration during exercise in the heat, but they remain stable or elevated during exercise in the cold [17]. Hence, the effects of environmental heat stress and dehydration interact to magnify the magnitude of physiological strain in conditions of limited evaporative cooling. Hyperthermia is a common feature of exercise-induced dehydration in the heat, whereas in the cold the same level of dehydration produces lower thermal, cardiovascular, metabolic and perceptual strain. Therefore, the greatest haemodynamic disturbances are seen during exercise in the heat when progressive dehydration and hyperthermia are combined.

A progressive fall in $\dot{Q}$ is a key hallmark of the dehydration-induced cardiovascular strain observed during prolonged, strenuous whole-body exercise in the heat (Fig. 2) [44-46] and thermoneutral environments [47]. This response is prevented in trained partially heat-acclimated individuals by maintaining euhydration via ingestion of fluid during exercise $[26,45,47,48]$. Concomitant with the declining $\dot{Q}$, heart rate rises continuously, whereas stroke volume declines by $\sim 30 \%[48,49]$, secondary to the rise in core body temperature and heart rate and the loss in blood volume likely limiting ventricular filling $[48,50]$. Comparable core hyperthermia alone does not reduce stroke volume to the same extent (7-8\%), and a number of studies show that $\dot{Q}$ during hyperthermic submaximal exercise is elevated, rather than reduced [2, 51-53]. These contrasting findings suggest that compromised $\dot{Q}$ is dependent on the extent of the cardiovascular challenge induced by combined stress evoked by dehydration, hyperthermia and exercise, or, more specifically, the overall functional demand, which is inversely related to the body functional reserve or capacity to adjust to homeostatic alterations exemplified in this case by circulatory adjustments to stroke volume reductions. To provide support for this notion, our laboratory has explored the impact of progressive dehydration on central haemodynamics at rest 
and during exercise of a low physiological load (i.e., single leg knee-extensor exercise) [54]. Progressive dehydration reduced blood volume $(\sim 5 \%)$ and lowered stroke volume $(\sim 20 \mathrm{~mL})$ to a similar degree to that seen in the whole-body exercise paradigm, with the fall in stroke volume coupled to a substantial fall in end-diastolic volume (EDV), with only a small fall in end-systolic volume (ESV) and a marked elevation in heart rate $(\sim 30 \mathrm{bpm})$ compared to control (hydrated) values. Intriguingly, however, and in contrast to whole-body exercise, $\dot{Q}$ was maintained at rest and during single leg knee-extensor exercise across all the hydration manipulations. It therefore appears that the extent of the total muscle mass recruited, and by extension the physiological demands of the exercise, plays an important role in determining the cardiovascular strain severity induced by dehydration and hyperthermia.

\subsection{Peripheral and Cardiac Factors Reducing Stroke Volume with Dehydration and Hyperthermia}

Classically, stroke volume is thought to be determined by intrinsic factors within the heart itself (i.e., cardiac mechanics, contractility and filling time) and extrinsic factors associated with alterations in preload (i.e., venous return) and afterload (i.e., arterial blood pressure and peripheral vascular resistance). The contribution of these intrinsic and extrinsic mechanisms to the dehydration-induced stroke volume reduction are discussed below, starting with the intrinsic cardiac factors. Firstly, it seems that at rest and during exercise of a low cardiovascular demand, when $\dot{Q}$, mean arterial pressure, systemic vascular resistance, cardiac ejection fraction and left ventricle (LV) mechanics are stable, the reduction in stroke volume is unrelated to changes in LV function [54]. Measures of systolic twist and basal rotation velocity (e.g. LV mechanics) are largely maintained or somewhat enhanced by dehydration [54], similar to findings during intermittent, submaximal exercise [55]. We cannot rule out the possibility that more substantial body mass losses in combination with more prolonged, high-intensity exercise negatively affect $\mathrm{LV}$ function and contribute to large stroke volume decline. In this light, some evidence suggests a depressed regional strain, torsion and untwisting velocity following an ultra-endurance activity inducing a body mass loss of $\sim 4.5 \%$ [56]. However, the observation that $\dot{Q}$ is elevated following endurance exercise indicates that cardiac performance overall is not impaired during recovery. Moreover, the lack of effect of dehydration at rest and with low-intensity exercise [54] lends support to the argument that altered LV mechanics do not contribute to the stroke volume reduction with dehydration. Secondly, the fall in ESV with progressive dehydration at rest and small muscle mass exercise is indicative of an enhanced rather than a depressed cardiac contractility [54]. Thirdly, the progressive reduction in cardiac filling time secondary to the increase in heart rate could contribute to the reduction in stroke volume with dehydration, as seen during prolonged submaximal exercise in the heat $[50,57,58]$. The increase in heart rate is a response to reduced blood volume, and elevations in core temperature and sympathoadrenal activity [48, 59]. The contribution of cardiac tachycardia to the reduced stroke volume with dehydration is backed by the observations that (1) raising heart rate, by right atrial pacing, leads to reductions in stroke volume at any given exercise intensity [60], and (2) use of $\beta 1$-adrenergic blockade during prolonged exercise prevents both the normal increase in heart rate and the normal reduction in stroke volume, probably because of the relatively longer diastolic filling time $[50,57]$. Hence intrinsic factors such as cardiac contractility and mechanics do not seem to be the mechanisms explaining the stroke volume decline with dehydration and hyperthermia, but the reduction in filling time accompanying the ensuing tachycardia is an important factor.

On the other hand, the role of extrinsic factors in the stroke volume decline can be examined by scrutinising the mean arterial pressure and LV volume responses. Augmented afterload is not a factor as progressive dehydration lowers arterial pressure [48]. Instead, the diminished LV end-diastolic volume and lowered femoral beat volume indicate that venous return is compromised in conditions of dehydration and hyperthermia $[26,54]$. The lower circulating blood volume resulting from the water losses via sweat and the enhanced peripheral vasoconstriction are two factors associated with the lesser venous return and left ventricular filling. These observations challenge the idea that the decline in $\dot{Q}$ causes the reduction in peripheral blood flow. On the contrary, it seems based on the responses of the different components of Ohm's law that peripheral mechanisms restricting blood flow and thus venous return to the heart might account for most of the $\dot{Q}$ decline with dehydration and hyperthermia [60] (see further discussion in section 4). Although this hypothesis warrants further investigation, the evidence reviewed here disputes a dominant cardiac limitation, and instead suggests that the cardiac stroke volume decline with dehydration and hyperthermia at rest and during exercise is to a large extent the result of the reduced ventricular filling owing to lower venous return and filling time.

\section{Heat, Hydration and the Skeletal Muscles}

The skeletal muscle circulation mirrors the dehydrationinduced central haemodynamic alterations, at rest and during isolated-limb and strenuous whole-body exercise. At rest, limb blood flow and limb vascular conductance (limb blood flow/limb perfusion pressure) are enhanced with progressive dehydration, a response maintained during small muscle mass 

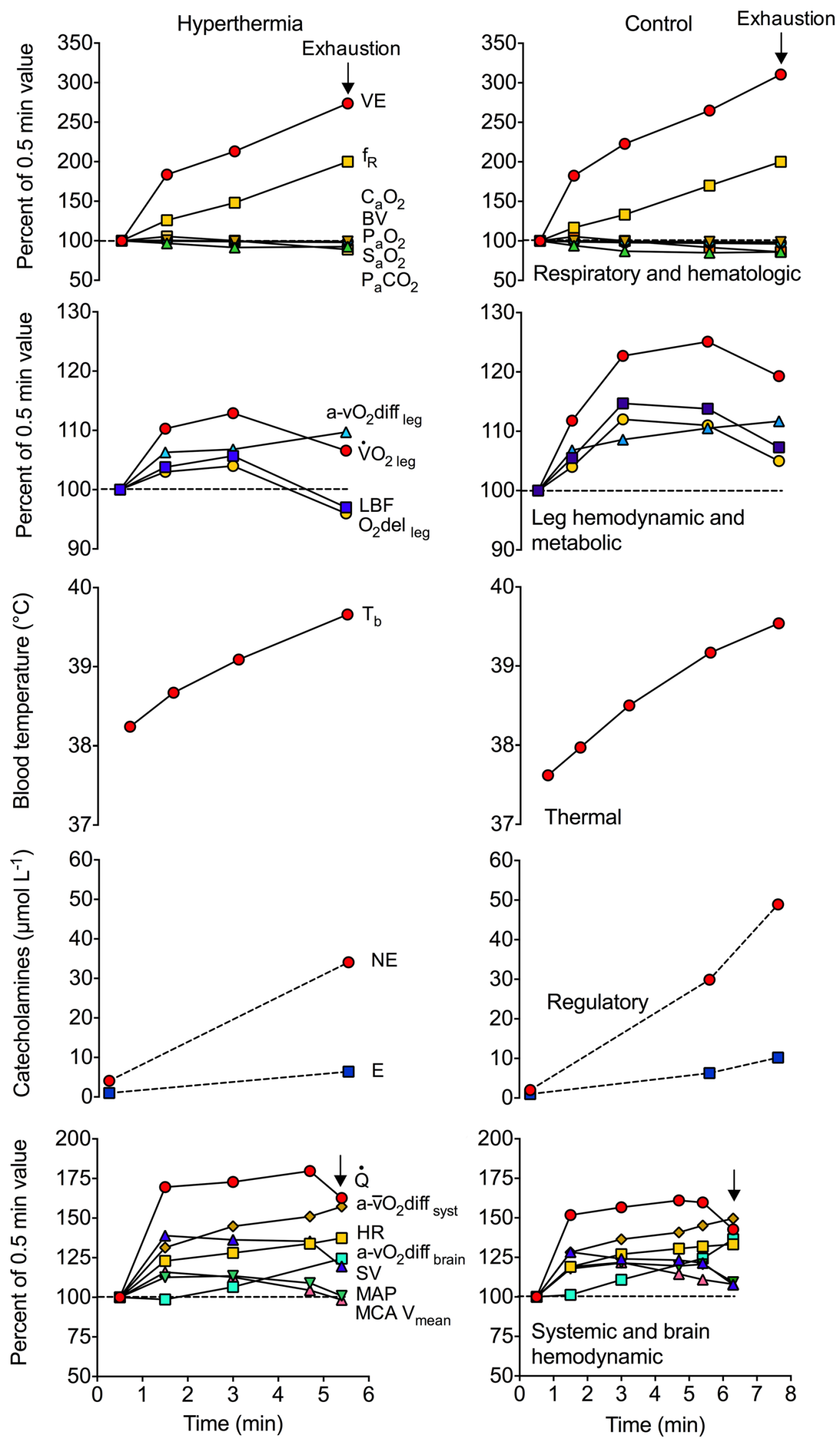
4Fig. 2 Effects of hyperthermia on respiratory, haematological, regional cardiovascular, metabolic, thermal and regulatory responses to maximal aerobic exercise and maximal endurance capacity. The over-time physiological responses are reported as a percentage of the 0.5 -min exercise value, or in the case of the thermal and catecholamine responses, the delta increase in locomotor limb blood temperature and the absolute concentration values, respectively. Thermal strain was higher at the onset of constant load cycling $(\sim 360 \mathrm{~W})$ in the whole body hyperthermia condition $\left(+1{ }^{\circ} \mathrm{C}\right.$ and $10{ }^{\circ} \mathrm{C}$ higher in $T_{\text {es }}$ and $T_{\text {sk }}$, respectively), and was associated with significant respiratory, cardiovascular, metabolic and regulatory strain after $3 \mathrm{~min}$ of cycling, leading to an accelerated fatigue ( $5.5 \mathrm{vs}$. $7.6 \mathrm{~min}$ ). Note that the reductions in locomotor limb blood flow prior to exhaustion in both conditions led to a reduction in $\mathrm{O}_{2}$ delivery and a depressed exercising limb muscle $\dot{V} O_{2}$, even though $\mathrm{O}_{2}$ extraction increased. Therefore, the faster fatigue with hyperthermia and dehydration during exercise requiring aerobic capacity seems to be closely coupled with impaired muscle metabolism. Drawn from mean data reported by González-Alonso and Calbet [35] and González-Alonso et al. [107]. $V E$ ventilation, $f_{R}$ respiratory rate, $\mathrm{C}_{\mathrm{a}} \mathrm{O}_{2}$ arterial oxygen content, $\mathrm{BV}$ blood volume, $\mathrm{P}_{a} \mathrm{O}_{2}$ arterial oxygen partial pressure, $\mathrm{S}_{a} \mathrm{O}_{2}$ arterial oxygen saturation, $P_{a} \mathrm{CO}_{2}$ arterial carbon dioxide partial pressure, $a-v O_{2}$ diff ${ }_{\text {leg }}$ arterio-venous oxygen content differences across the leg, $\dot{V} O_{2 l e g}$ leg oxygen uptake, $L B F$ leg blood flow, $\mathrm{O}_{2} \mathrm{del}_{\text {leg }}$ oxygen delivery to the leg, $T_{b}$ blood (femoral venous) temperature, $N E$ norepinephrine, $E$ epinephrine, $\dot{Q}$ cardiac output, $a-v O_{2}$ diff ${ }_{\text {syst }}$ systemic arterio-mixed venous oxygen content differences, $H R$ heart rate, $a-v O_{2}$ diff $f_{\text {brain }}$ arterio-mixed venous oxygen content differences across the brain, $S V$ stroke volume, MAP mean arterial pressure, $M C A V_{\text {mean }}$ middle cerebral artery mean blood flow velocity

exercise, despite substantial body mass losses $(\sim 3.5 \%)$ and reductions in limb perfusion pressure [61]. Conversely, during prolonged, whole-body exercise, the substantial fall in stroke volume $\left(47 \mathrm{~mL}_{\text {beat }}{ }^{-1}\right)$ and $\dot{Q}\left(\sim 4 \mathrm{~L} \mathrm{~min}^{-1}\right)$ is associated with $\mathrm{a} \sim 2 \mathrm{~L} \mathrm{~min}^{-1}$ reduction in locomotor limb blood flow compared to control exercise [26] (see Fig. 3, left-hand panel). The marked fall in active limb blood perfusion during whole-body exercise, despite marked body hyperthermia, is offset when fluid intake matches fluid loss [26, 62], and when systemic haemodynamics are normalised (compared to upright control conditions) by exercising in a supine or semirecumbent position $[14,63]$. This close coupling between exercising limb and systemic haemodynamics is not surprising in light of the observations that pharmacologicallyinduced limb vasoconstriction (via intra-arterial infusion of adenosine and the sympathomimetic agent tyramine, or the combined blockade of prostaglandins and nitric oxide using NG-monomethyl-L-arginine and indomethacin infusion) decreases $\dot{Q}$ in proportion to the decrease in limb blood flow $[64,65]$, whereas limb vasodilation (via intra-arterial infusion of ATP and other nucleotides) leads to a proportional increase in limb blood flow and $\dot{Q}[66,67]$, a relationship also present during hyperthermia-mediated limb hyperemia [68, 69], heat stress exercise $[35,38]$ and alterations in erythrocyte count and oxygenation state of haemoglobin [67]. Taken together, the exercising limb and systemic haemodynamic responses to dehydration are intimately linked, such that active skeletal muscle vasoconstriction may lead to compromised $\dot{Q}$ during whole body exercise at least in part by inducing reductions in venous return, left ventricular filling and ultimately stroke volume.

\subsection{Mechanisms of Blood Flow Control during Dehydration and Hyperthermia}

Several local and central regulatory mechanisms may explain these differential limb haemodynamic responses to dehydration under resting and different exercise conditions. The limb blood flow responses to small muscle mass and whole-body exercise with varied hydration status can be interpreted using Ohm's law, as the net consequence of alterations in either perfusion pressure, local vascular conductance or both. The main determinant of limb vascular conductance, the inverse of resistance, is the change in diameter of the resistance arterioles located in the muscle microcirculation. A decrease in limb vascular conductance is indicative of vasoconstriction (decreased vessel diameter), whereas an increase indicates vasodilation (increased vessel diameter). In this construct, the small increase in limb blood flow seen in small muscle mass exercise must be due to net local vasodilation, as mean arterial and limb perfusion pressure were slightly but significantly suppressed [61]. The interplay between locally released vasodilator factors and sympathetic vasoconstrictor activity primarily regulates active muscle blood flow [70-72]. It is possible that thermal, fluid and oxygen-sensing mechanisms activated by (1) increases in local tissue temperature similar to that observed during local and whole-body passive heating [68, 69, 73-75], (2) reductions in cellular volume, and (3) elevations in arterial oxygen content concomitant with the dehydration-mediated haemoconcentration $[61,76]$ together lead to augmented vasodilator activity in the face of a very low systemic sympathetic activity (e.g. circulating noradrenaline 1.2-1.9 $\mathrm{nmol} \mathrm{L}^{-1}$ ). This contrasts with the responses to whole body prolonged exercise where a similar fall in mean arterial pressure $(\sim 8 \%)$ is accompanied by a much larger increase in circulating catecholamines $\left(\sim 18 \mathrm{nmol} \mathrm{L}^{-1}\right)$. Paradoxically, however, vascular conductance is essentially unchanged or slightly enhanced $[26,61]$. This observation is similar to those seen during constant-load, maximal exercise with superimposed body hyperthermia [35]. Taken as a whole, these findings (based on whole limb vascular conductance data) suggest that there is little or no role for actual vasoconstriction in the reduced exercising muscle blood flow with dehydration and hyperthermia during whole body exercise, but rather this is a passive event caused by the overall circulatory strain and manifested in conditions of high physiological load. Regardless of the mechanism, the large fall in active-muscle perfusion during strenuous whole-body exercise can reduce $\mathrm{O}_{2}$ supply, which is initially compensated by increases in oxygen 
extraction, but in conditions requiring near or maximal aerobic capacity would eventually lead to compromised local and systemic aerobic metabolism and accelerated fatigue, as discussed in section $6[34,35]$.

\section{Heat, Hydration and the Brain}

Despite its relatively small contribution to total body weight, the human brain is a highly metabolically active organ, accounting for $\sim 20 \%$ of whole-body aerobic metabolism and $15 \%\left(750 \mathrm{~mL} \mathrm{~min}^{-1}\right.$ or $\sim 52 \mathrm{~mL} 100 \mathrm{~g}^{-1} \mathrm{~min}^{-1}$ ) of the resting $\dot{Q}$ [77-79]. The brain does not have the capacity to store oxygen and so the maintenance of its high metabolic demand is dependent on the provision of oxygen, and other metabolic substrates, and removal of metabolic by-products, by the circulation. How exhaustive exercise and stressors such as hyperthermia and dehydration interact to affect the human brain circulation and metabolism has been a major focus of research in the last two decades. We first discuss how cerebral blood flow (CBF) is altered in response to an exercise stimulus, before delving into the impact of hyperthermia and dehydration, and their effect on cerebral metabolism.

In the rest-to-exercise transition, $\mathrm{CBF}$ was originally shown to remain unchanged [80-85]. These investigations, however, used the Kety-Schmidt method, which determines global (i.e., whole-brain) $\mathrm{CBF}$ by first saturating the cerebral tissue with an inert gas (e.g. nitrous oxide $\left[\mathrm{N}_{2} \mathrm{O}\right]$ ), before determining the ratio between the rate of $\mathrm{N}_{2} \mathrm{O}$ uptake and the arterial to internal jugular venous $\mathrm{N}_{2} \mathrm{O}$ difference by the application of the Fick principle. There are limitations that can undermine these measurements during whole-body strenuous exercise including: (1) the requirement for exercise to be of sufficient duration ( $15 \mathrm{~min}$ ) and of a steady-state nature (not the case during high or severe intensity exercise domains) [86], and (2) the observation that the main sampling site for obtaining venous blood drained from the brain (the internal-jugular vein) is temporally collapsed during upright exercise [87, 88], thus leading to heterogeneity of the venous drainage with the potential to miss the important metabolic profile of the brain [89]. More recent methodological approaches with good temporal resolution consistently show an exercise-induced increase in CBF by $20 \%$ up to moderate exercise intensities [87, 90-101]. Thereafter, CBF remains elevated throughout the duration of prolonged exercise in the moderate-intensity domain (e.g. $\leq \sim 60 \% \dot{V} \mathrm{O}_{2 \max }$ ) [100], but CBF is markedly suppressed when exercise intensity is increased, often returning to near resting values prior to exhaustion [38, 87, 94, 95, 97].

At rest, elevations in core temperature (e.g. by $+1.5^{\circ} \mathrm{C}$ ) reduce $\mathrm{CBF}$ by $\sim 15 \%$ [102], whereas dehydration without concomitant hyperthermia elevates CBF [103]. Hyperthermia and dehydration also alter the $\mathrm{CBF}$ dynamics during different types of exercise. For example, CBF (MCA $V_{\text {mean }}$;
Fig. 3 Effects of progressive dehydration and maintenance of euhydration by fluid ingestion on respiratory, hematologic, cardiovascular, metabolic, thermal and regulatory responses to prolonged exercise and submaximal endurance capacity in the heat. The over-time physiological responses are reported as percentage of the 20-min exercise value, or in the case of the thermal responses the delta increase in regional temperature. The physiological responses were not different between trials at this reference time point, as participants' hydration status was the same. Note, however, that progressive dehydration was associated with significant physiological and perceptual strain preceding exhaustion, as reflected by gradual hyperventilation, haemoconcentration, increased arterial oxygen content, arterial hypocapnia, cardiovascular strain with reductions in brain, contracting skeletal muscle and skin perfusion, cardiac output and perfusion pressure, core and active muscle hyperthermia, alterations in neural activity, increases in perception of effort, but to a large extent maintained exercising limb, brain and systemic aerobic metabolism owing to the corresponding increases in leg, brain and systemic in oxygen extraction. This contrasts with the apparent maintenance of physiological homeostasis and perception of effort during the euhydration trial, in which athletes could have continued cycling for some additional 15-60 min before reaching exhaustion. Drawn from mean data reported by González-Alonso et al. [26, 137]. The cerebral blood flow responses were drawn from data reported by Trangmar et al. [106]. $f_{R}$ respiratory frequency, $V E$ ventilation, $P_{a} O_{2}$ arterial oxygen tension, $\mathrm{P}_{a} \mathrm{CO}_{2}$ arterial carbon dioxide tension, $\mathrm{C}_{a} \mathrm{O}_{2}$ arterial oxygen content, $\mathrm{S}_{a} \mathrm{O}_{2}$ arterial oxygen saturation, $B V$ blood volume, $H R$ heart rate, $S V$ stroke volume, $\dot{Q}$ cardiac output, $M A P$ mean arterial pressure, $L B F$ leg blood flow, $T P R$ total peripheral resistance, $F B F$ forearm blood flow, $C B F$ cerebral blood flow, $a-v O_{2} \operatorname{diff}_{\text {brain }}$ arterio-venous oxygen content differences across the brain, $a-v O_{2}$ diff ${ }_{\text {syst }}$ systemic arteriomixed venous oxygen content differences, $a-v \mathrm{O}_{2}$ diff ${ }_{l e g}$ arterio-venous oxygen content differences across the exercising leg, $V O_{2 \text { syst }}$ systemic oxygen uptake $\dot{V} O_{2 \text { leg }}$ leg oxygen uptake, $T_{b}$ blood (femoral) temperature, $T_{m}$ muscle (vastus lateralis) temperature, $T_{e s}$ oesophageal temperature, $N E$ norepinephrine, $E$ epinephrine

middle cerebral artery mean blood flow velocity) is suppressed throughout the duration of self-paced time trial, or markedly reduced by $\sim 15-25 \%$ when hyperthermia develops in an uncompensable environment compared to a cool or thermoneutral environment [100, 104, 105]. The development of dehydration ( $\geq 3 \%$ body mass loss) during prolonged exercise in the heat causes further cerebrovascular instability by hastening the decline in $\mathrm{CBF}$, concomitant with an elevated hyperthermia, tachycardia and early fatigue [106]. On the other hand, the reduction in CBF is attenuated when fluid intake matches bodily fluids lost through sweating. The effect of hyperthermia and dehydration on CBF is not isolated to prolonged exercise, as the typically observed fall in CBF during severe-intensity exercise is accelerated (i.e. occurring at a lower work rate or shorter duration of exercise) in an uncompensable hot environment [38, 107]. This is also the case when dehydrated individuals perform incremental exercise in a compensable hot environment [108], where dehydration and concomitant hyperthermia reduce $\mathrm{CBF}$ to values equivalent to control conditions, but at a significantly lower absolute work rate ( $\sim 270$ vs. $\sim 340 \mathrm{~W})$ (Fig. 4). The CBF dynamics are, however, normalised to 

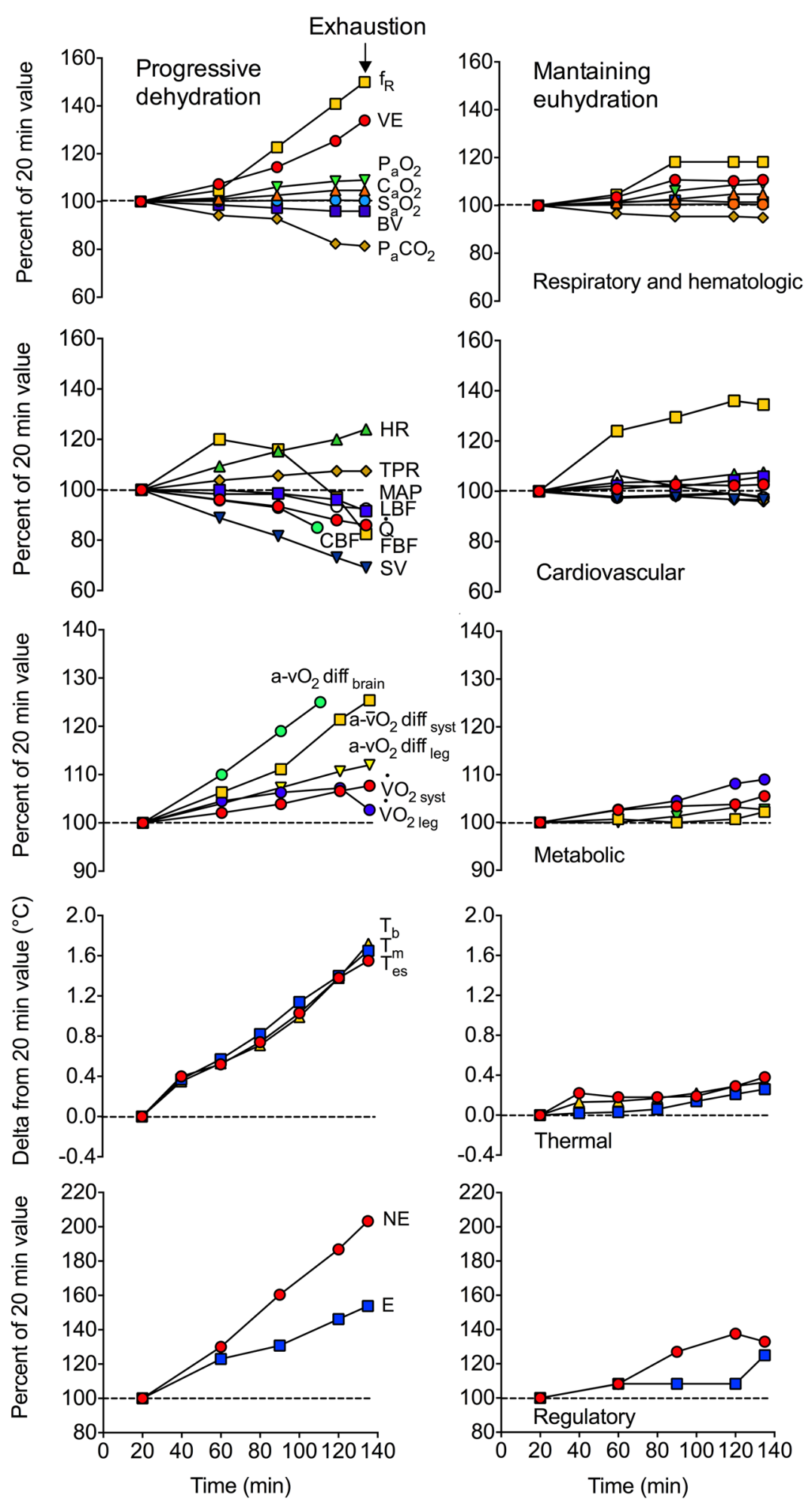

control conditions when participants maintained their normal hydration status [108]. In summary, exercise in the heat evoking severe body hyperthermia compromises cerebral perfusion during strenuous submaximal and maximal exercise. The development of dehydration enhances the cerebrovascular strain and accentuates the fall in CBF.

\subsection{Mechanisms of CBF Control during Dehydration and Hyperthermia}

The compromised CBF seen during exercise in the heat, with and without dehydration, is coupled with a fall in cerebrovascular conductance [108]. The precise regulation 

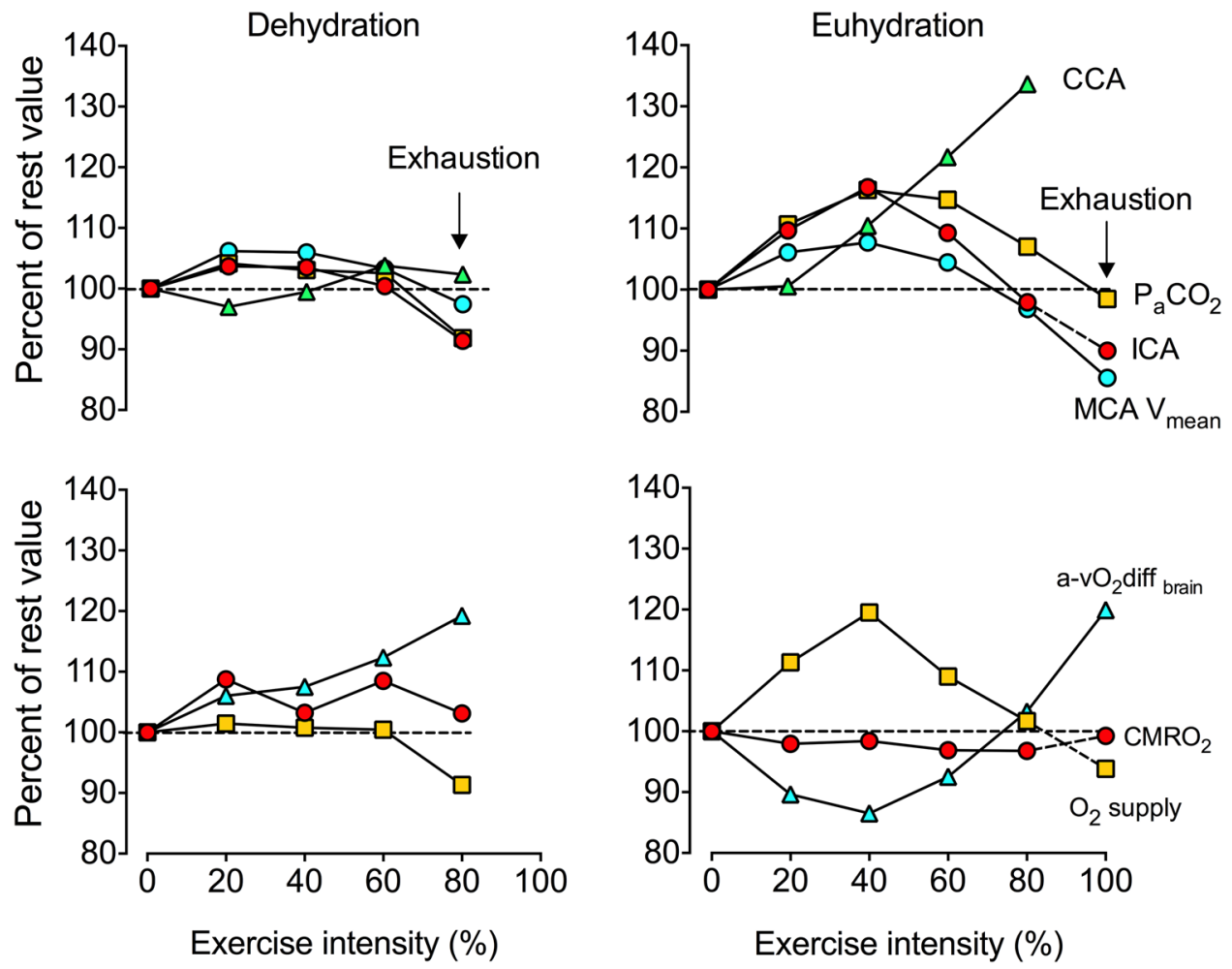

Fig. 4 Effects of dehydration on cerebral haemodynamics and metabolism. Cerebral haemodynamic and metabolic responses during incremental cycling to exhaustion reported as percent rest reference value. Of note are the declines in cerebral blood flow and oxygen supply at about $60 \%$ of maximal aerobic exercise intensity, which are paralleled by proportional increases in oxygen extraction across the brain, such that cerebral aerobic metabolism is maintained. Drawn from

mean data reported by Trangmar et al. [108]. CCA common carotid artery blood flow, ICA internal carotid blood flow, $\mathrm{P}_{a} \mathrm{CO}_{2}$ arterial carbon dioxide partial pressure, $M C A V_{\text {mean }}$ middle cerebral artery mean blood flow velocity, $a$ - $\mathrm{O}_{2}$ diff brain $_{\text {in }}$ differences in oxygen content across the brain, $\mathrm{O}_{2}$ supply oxygen delivery to the brain which is the product of cerebral blood flow and arterial oxygen content, $\mathrm{CMRO}_{2}$ cerebral metabolic rate for oxygen

of cerebrovascular tone is inherently complex, potentially involving many different respiratory, metabolic and neural signals $[109,110]$. The combination of hyperthermia, dehydration and strenuous exercise augments circulating noradrenaline; however, the direct effect of enhanced sympathetic vasoconstrictor activity on the cerebral vasculature is as yet unclear [111]. A more likely candidate explaining the fall in $\mathrm{CBF}$ in the hyperthermic and dehydrated athlete is the hyperthermia-induced hyperventilation and concomitant lowering of the partial pressure of arterial $\mathrm{CO}_{2}\left(\mathrm{P}_{\mathrm{a}} \mathrm{CO}_{2}\right)$ [100, 108]. Progressive reductions in $\mathrm{P}_{\mathrm{a}} \mathrm{CO}_{2}$ reduce $\mathrm{CBF}$ in the resting human [112] and account for all of the reduction in CBF during severe passive hyperthermia $[113,114]$. A reduced $\mathrm{P}_{\mathrm{a}} \mathrm{CO}_{2}$ also plays a prominent role in the fall in $\mathrm{CBF}$ during prolonged exercise in the heat [100], and with superimposed dehydration [106]. The early fall in CBF when dehydrated is associated with a higher core temperature and hyperventilation and a greater fall in $\mathrm{P}_{\mathrm{a}} \mathrm{CO}_{2}[108]$.

\subsection{Heat, Hydration and Cerebral Aerobic Metabolism}

The early reductions in CBF seen during strenuous exercise in the heat, with and without dehydration, have been postulated to reduce cerebral oxygenation [115]. A lower vascular and neuronal oxygenation could potentially compromise the cerebral metabolic rate for oxygen $\left(\mathrm{CMRO}_{2}\right)$, thereby contributing to the overall process of fatigue [115], reductions in motor output $[116,117]$ and reductions in cognitive performance [118-121] that are magnified in hot environments and/or when dehydrated $[118,122-124]$. The characterisation of the $\mathrm{CMRO}_{2}$ dynamics during exhaustive exercise is therefore a key question in integrative human physiology. $\mathrm{CMRO}_{2}$ is calculated using the Fick principle, as $\mathrm{CBF} \times$ the arterial-to-jugular venous $\mathrm{O}_{2}$ content difference (or $\mathrm{O}_{2}$ extraction). The available, albeit limited, data indicate that $\mathrm{CMRO}_{2}$ is largely unaltered from rest-to-moderate intensity exercise [82, 83, 87], before seemingly increasing close to maximal intensities [107, 115, 125, 126]. It could be 
anticipated that the accelerated reductions in CBF seen with dehydration and hyperthermia during exercise in the heat would be accompanied by a decrease in the $\mathrm{CMRO}_{2}$. However, the available evidence does not support this idea. In two studies, $\mathrm{CMRO}_{2}$ appears to even increase during exhaustive exercise, as the increase in cerebral $\mathrm{O}_{2}$ extraction was greater than the fall in CBF (up to $32 \%$ vs. 15-20\%) [104, 107]. The increase in $\mathrm{CMRO}_{2}$ was postulated to be due to the substantial core hyperthermia and related $\mathrm{Q}_{10}$ effect, and the heightened 'cognitive' effort to maintain the required physiological output when exercising in the heat. Further supporting that $\mathrm{CMRO}_{2}$ is not compromised, we recently observed a maintained $\mathrm{CMRO}_{2}$ during exercise in the heat across a range of exercise intensities and hydration states (Figs. 3 and 4). However, we did not see the previously reported increase during exhaustive exercise, as the CBF reductions and the compensatory increases in cerebral $\mathrm{O}_{2}$ extraction were proportional. The differential $\mathrm{CMRO}_{2}$ responses (increased vs. maintained $\mathrm{CMRO}_{2}$ ) are likely due to methodological differences in the calculation of $\mathrm{CMRO}_{2}$, specifically, whether CBF is obtained globally by the Kety-Schmidt method [104], or regionally using assumed values [107]. It is likely that global $\mathrm{CMRO}_{2}$ is underestimated when $\mathrm{CMRO}_{2}$ is quantified using oxygenation values measured in the internal jugular vein, and in our case volumetric $\mathrm{CBF}$ was only measured in the internal carotid artery (ICA; perfusing 75-80\% of the brain) [106, 108], which could be somewhat different to the responses of the posterior cerebral circulation [92, 95]. Ideally, blood flow in the vertebral arteries (accounting for the remaining $20 \%$ of CBF) and oxygenation in the vertebral veins should be assessed simultaneously [127]. Notwithstanding these limitations, these studies consistently show a large cerebral $\mathrm{O}_{2}$ extraction reserve and a maintained or enhanced $\mathrm{CMRO}_{2}$, even in the most strenuous of exercise conditions, and therefore a reduced global cerebral oxygen metabolism is unlikely to explain the early fatigue seen in hot conditions while in the dehydrated and/or hyperthermic state.

\section{Heat, Hydration and the Mechanisms of Fatigue}

In the following sections, we present two mechanistic figures to attempt to explain the primary cardiovascular and metabolic consequences of combined dehydration and hyperthermia during submaximal and maximal endurance performance. Notwithstanding this focus, it is important to recognise that the development of fatigue during strenuous exercise in the heat is a complex phenomenon, possibly involving multiple signals and processes originating in different bodily tissues and organs. In this light, the early fatigue seen during both submaximal and maximal exercise could be the net result of (but not limited to) (1) respiratory, cardiovascular and metabolic strain, (2) alterations in the

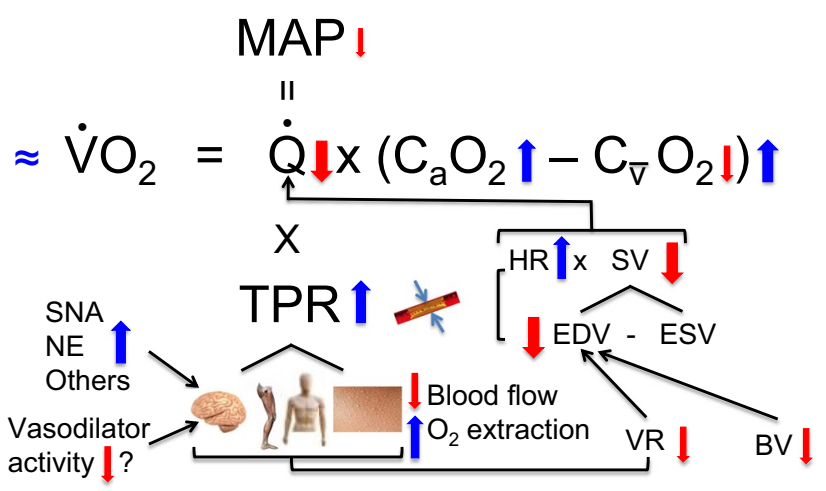

Fig. 5 Schematic diagram illustrating the effects of dehydration and hyperthermia on physiological function during submaximal exercise, according to Ohm's law and the Fick principle. Significant dehydration and hyperthermia (i.e., $4-5 \%$ body mass loss and $40-41{ }^{\circ} \mathrm{C}$ core and muscle temperatures) impair submaximal endurance capacity in athletes. The compromised performance occurs in association with reductions in systemic and regional tissue and organ blood flow, but compensatory physiological adjustments maintain whole-body oxygen uptake. For a full description, see section 6.1. The direction of the arrow indicates the direction of response, whereas its size indicates the magnitude of the response. $\dot{Q}$ cardiac output, $T P R$ total peripheral resistance, $M A P$ mean arterial pressure, $B V$ blood volume, $V R$ venous return, $S N A$ sympathetic nerve activity, $N E$ circulating noradrenaline concentration, $\mathrm{C}_{a} \mathrm{O}_{2}$ arterial oxygen content, $\mathrm{C}_{v} \mathrm{O}_{2}$ mixed venous oxygen content, $H R$ heart rate, $S V$ stroke volume, $E D V$ end-diastolic volume, $E S V$ end-systolic volume

functioning of the central nervous system, neurotransmitter activity and central motor output, and (3) psychophysiological factors relating to motivation, perceptions of effort and thermal comfort $[12,13,128]$. Moreover, the extent of the ensuing physiological strain is also dependent on the degree of heat acclimation and aerobic fitness of participants, as these factors have a bearing on the capacity to cope with heat stress exercise $[14,45,48]$. The highest physiological strain is expected to happen in untrained and unacclimated subjects who perform strenuous exercise in a hot and humid environment. Elite high performance and heat-acclimated athletes will be on the other end of a continuum and show minimal alterations in physiological function under comparable exercise and environmental stress [129].

\subsection{Mechanisms of Performance Limitation in Submaximal Exercise}

The severe physiological strain induced by significant dehydration and hyperthermia is associated with the impaired submaximal endurance capacity in athletes and is typified by marked declines in blood flow to active skeletal muscle, skin and brain and $\dot{Q}$, a substantial increase in total peripheral resistance and a small reduction in mean arterial pressure or perfusion pressure (Fig. 5) [26, 45, 48, 49]. The reduction in $\dot{Q}$ is primarily related to the lowering in stroke volume, 
owing to the hyperthermia-induced cardiac tachycardia [48, $50,57,58]$ and concomitant reductions in blood volume and venous return [17]. The latter is related to peripheral vasoconstriction occurring in the brain, active skeletal muscle, skin and perhaps other upper body organs and tissues such as visceral organs. Lower tissue blood flow is related to the interaction between increases in vasoconstrictor activity (including sympathetic nerve activity) and alterations in vasodilator activity, although their specific contributions are as yet unknown [72]. Notwithstanding, the reductions in systemic, brain, locomotor limbs, skin and upper body tissues and organs blood flow and $\mathrm{O}_{2}$ supply are compensated for by increases in tissue $\mathrm{O}_{2}$ extraction, such that whole body $\dot{V} \mathrm{O}_{2}$ is preserved [26]. The development of fatigue, when dehydrated and hyperthermic, during prolonged submaximal exercise is associated with the attainment of near to maximal heart rate and an augmented internal body temperature [45, $48,130]$, the latter with implications for the central nervous system [131]. However, identifying the precise mechanism is challenging, given the multitude of circulatory, respiratory, perceptual and central processes, occurring simultaneously, that interrelate to advance fatigue $[12,13]$.

\subsection{Mechanisms of Performance Limitation in Maximal Exercise}

Figure 6 outlines how the severe physiological strain induced by significant dehydration and hyperthermia impairs exercise capacity at intensities close to or at $\dot{V} \mathrm{O}_{2 \max }$. In accordance with the Fick principle, the maximal convective $\mathrm{O}_{2}$ transport and $\mathrm{O}_{2}$ extraction (a- $\left.\mathrm{vO}_{2 \text { diff }}\right)$ set the upper limit for local tissue and systemic $\dot{V} \mathrm{O}_{2}$. Systemic, active skeletal muscle and brain $\mathrm{O}_{2}$ delivery are markedly suppressed during high-intensity exercise to volitional exhaustion [35, 95, 107, 132, 133] and, as outlined in sections 4 and 5, the early fatigue with dehydration and hyperthermia is associated with a faster decline in peripheral blood perfusion. The early attenuation in the rate of $\mathrm{O}_{2}$ delivery is temporally associated with the attainment of the limit of functional $\mathrm{O}_{2}$ extraction reserve ( $\sim 90 \%)$ across the locomotor limbs, with the consequence that active skeletal muscle $\dot{V} \mathrm{O}_{2}$ and $\dot{V} \mathrm{O}_{2 \max }$ are blunted [35, 38]. Contrastingly, the brain does not appear to attain the limit of its functional $\mathrm{O}_{2}$ reserve at exhaustion $(\sim 40 \%)$ and, despite a marked fall in $\mathrm{CBF}, \mathrm{CMRO}_{2}$ is preserved [108]. The decline in $\dot{Q}$ seen during maximal exercise, with and without hyperthermia and dehydration, is due to reductions in stroke volume (SV). In the context of the dehydrated and hyperthermic athlete exercising at maximal intensities, the fall in SV might be related to the reduction in EDV, owing to reductions in blood volume and the diminished venous return paralleling peripheral vasoconstriction (Fig. 6).

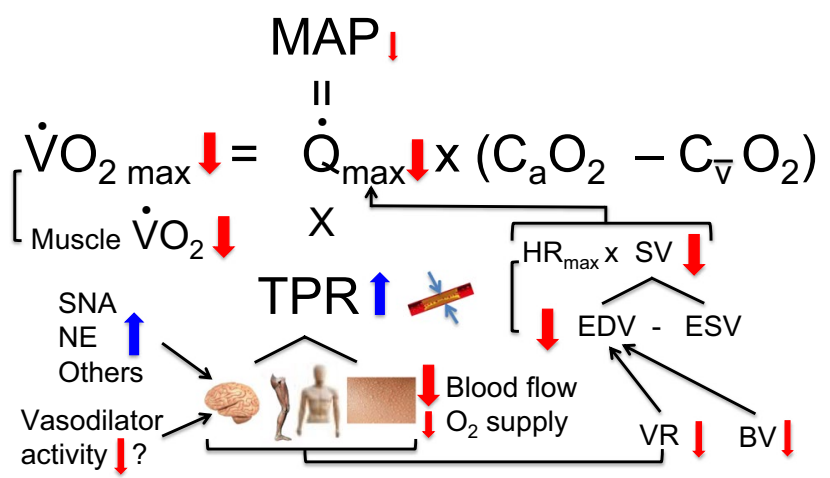

Fig. 6 Schematic diagram highlighting major physiological factors limiting maximal endurance capacity with and without dehydration and hyperthermia. Impaired maximal endurance capacity in dehydrated and hyperthermic athletes (i.e., $4-5 \%$ body mass loss and $39-40{ }^{\circ} \mathrm{C}$ core and muscle temperatures) is associated with a marked decline in cardiac output $(\dot{Q})$, a substantial increase in total peripheral resistance (TPR) and a small reduction in mean arterial pressure (MAP), or perfusion pressure. The concomitant reductions in peripheral blood flow and $\mathrm{O}_{2}$ supply lead to suppressed whole body and locomotor limb $\dot{V} O_{2}$ because the functional oxygen extraction reserve in active skeletal muscle has been exhausted. A lower stroke volume is also the main factor reducing $\dot{Q}$. Peripheral vasoconstriction is proposed as a major factor reducing venous return, cardiac filling and cardiac stroke volume. The direction of the arrow indicates the direction of response, whereas its size indicates the magnitude of the response. $\dot{Q}$ cardiac output, $T P R$ total peripheral resistance, $M A P$ mean arterial pressure, $B V$ blood volume, $V R$ venous return, $S N A$ sympathetic nerve activity, $N E$ circulating noradrenaline concentration, $\mathrm{C}_{a} \mathrm{O}_{2}$ arterial oxygen content, $\mathrm{C}_{v} \mathrm{O}_{2}$ mixed venous oxygen content, $H R$ heart rate, $S V$ stroke volume, $E D V$ end-diastolic volume, $E S V$ end-systolic volume

\subsection{Interaction of Environment and Exercise Intensity on Physiological Function}

The two scenarios presented above show that the combination of dehydration, hyperthermia and exhaustive exercise leads to considerable physiological strain underpinning functional alterations in multiple organs and tissues, which directly or indirectly could curtail exercise capacity. But as discussed in Sect. 3, 4 and 5, there are numerous conditions whereby global reductions in heart, active skeletal muscle and brain $\mathrm{O}_{2}$ delivery and tissue metabolism do not explain the development of fatigue. For instance when exercise intensity is low, or involves a small proportion of the total muscle mass, dehydration can reduce exercise duration [134], unrelated to reduced $\mathrm{O}_{2}$ delivery, $\dot{V} \mathrm{O}_{2}$ or the accumulation of muscle metabolites [52, 54, 61, 134]. Moreover, physiological function is largely preserved when exercise is performed in a cold environment $\left(\sim 8-10^{\circ} \mathrm{C}\right)[7,10,17$, $135]$, despite reductions in plasma and blood volume that might decrease stroke volume if exercise is prolonged and intense [17]. This idea is supported by evidence that fatigue also occurs when central and peripheral haemodynamics and 
body temperatures are stabilised during strenuous prolonged exercise in the heat, when participants match their sweat loss with a proportional intake of fluids (Fig. 3, right-hand panel) $[10,26,48,49]$. Thus, fatigue in exercise scenarios with apparent systemic physiological stability is likely to involve a number of local tissue, cellular and molecular mechanisms that are beyond the scope of this review, but which are comprehensively discussed elsewhere [136].

\section{Conclusions}

Submaximal and maximal endurance performance can be impaired by dehydration and body hyperthermia. The impaired physical performance is associated with a myriad of alterations in physiological function, including reduced oxygen delivery to multiple regional tissues and organs, enhanced reliance on muscle glycogen and cellular metabolism, changes in neural activity and in some exercise and environmental conditions requiring near to maximal functional capacity, compromised muscle aerobic metabolism and aerobic capacity. It is evident, however, that the level of dehydration, the intensity of the exercise and the external environmental conditions determine the extent to which general physiological function is impaired. As presented in this review, dehydration and hyperthermia can elevate blood flow to heart, active muscles and brain during low-intensity exercise. When exercise intensity is increased above moderate levels or when exercise duration is prolonged, brain, active muscle and systemic blood flow are gradually compromised, mechanistically associated with enhanced peripheral vasoconstrictor activity, suppressed venous return and cardiac filling that ultimately hinder cardiac output. This attenuation in peripheral blood flow has a different effect on regional tissue aerobic metabolism, where a compromised active muscle, but not brain, oxygen uptake is a likely precursor to early fatigue when severe intensity exercise is performed in hot environments whilst experiencing marked dehydration and hyperthermia. Future research should elucidate the contribution of extrinsic and intrinsic cardiac factors altering peripheral blood flow and cardiac output with manipulation of hydration and local and body temperatures, and explore any possible associations with the onset of fatigue during submaximal and maximal endurance exercise.

Acknowledgements This paper is part of a supplement supported by the Gatorade Sports Science Institute (GSSI). The supplement was guest edited by Lawrence L. Spriet, who attended a meeting of the GSSI Expert Panel in October 2017 and received honoraria from the GSSI, a division of PepsiCo, Inc., for his participation in the meeting. He received no honoraria for guest editing the supplement. Dr. Spriet suggested peer reviewers for each paper, which were sent to the Sports Medicine Editor-in-Chief for approval prior to being approached. Dr Spriet provided comments on each paper and made an editorial decision based on comments from the peer reviewers and the
Editor-in-Chief. Where decisions were uncertain, Dr Spriet consulted with the Editor-in-Chief. The dehydration and hyperthermia studies conducted by the authors of this review since 2010 were performed at the Centre for Human Performance, Exercise and Rehabilitation, Brunel University London. The authors would like to thank all research students and collaborators who played a crucial role in these and other studies conducted by the authors.

\section{Compliance with Ethical Standards}

Funding José González-Alonso attended a meeting of the GSSI Expert Panel in October 2017 and received an honorarium (consultancy fees paid to Brunel University London) from the GSSI for his meeting participation and writing of this manuscript. No other sources of funding were used to assist in the preparation of this review.

Conflict of interest José González-Alonso has received funding from the GSSI to undertake fundamental physiological research. The dehydration and hyperthermia studies conducted by José González-Alonso and Steven Trangmar at the Centre for Human Performance, Exercise and Rehabilitation, Brunel University London from 2010 to 2014 were partly supported by a grant from the GSSI.

Open Access This article is distributed under the terms of the Creative Commons Attribution 4.0 International License (http://creativeco mmons.org/licenses/by/4.0/), which permits unrestricted use, distribution, and reproduction in any medium, provided you give appropriate credit to the original author(s) and the source, provide a link to the Creative Commons license, and indicate if changes were made.

\section{References}

1. Rowell LB, Marx HJ, Bruce RA, Conn RD, Kusumi F. Reductions in cardiac output, central blood volume, and stroke volume with thermal stress in normal men during exercise. J Clin Invest. 1966;45:1801-16.

2. Rowell LB, Brengelmann GL, Murray JA. Cardiovascular responses to sustained high skin temperature in resting man. $\mathbf{J}$ Appl Physiol. 1969;27:673-80.

3. Rowell LB. Human cardiovascular adjustments to exercise and thermal-stress. Physiol Rev. 1974;54:75-159.

4. Cheuvront SN, Kenefick RW, Montain SJ, Sawka MN. Mechanisms of aerobic performance impairment with heat stress and dehydration. J Appl Physiol. 2010;109:1989-95.

5. Sawka MN, Young AJ, Cadarette BS, Levine L, Pandolf KB. Influence of heat stress and acclimation on maximal aerobic power. Eur J Appl Physiol Occup Physiol. 1985;53:294-8.

6. González-alonso J, Crandall CG, Johnson JM. The cardiovascular challenge of exercising in the heat. J Physiol. 2008;586:45-53.

7. Cheuvront SN, Kenefick RW. Dehydration: physiology, assessment, and performance effects. Compr Physiol. 2014;4:257-85.

8. Hancock PA, Vasmatzidis I. Effects of heat stress on cognitive performance: the current state of knowledge. Int J Hyperth. 2003; 19:355-72.

9. Cheung SS, McLellan TM. Heat acclimation, aerobic fitness, and hydration effects on tolerance during uncompensable heat stress. J Appl Physiol. 1998;84:1731-9.

10. Kenefick RW, Cheuvront SN, Palombo LJ, Ely BR, Sawka MN. Skin temperature modifies the impact of hypohydration on aerobic performance. J Appl Physiol. 2010;109:79-86. 
11. Cheuvront SN, Carter R 3rd, Castellani JW, Sawka MN. Hypohydration impairs endurance exercise performance in temperate but not cold air. J Appl Physiol. 2005;99:1972-6.

12. Sawka MN, Cheuvront SN, Kenefick RW. Hypohydration and human performance: impact of environment and physiological mechanisms. Sports Med. 2015;45:51-60.

13. Nybo L, Rasmussen P, Sawka MN. Performance in the heatphysiological factors of importance for hyperthermia-induced fatigue. Compr. Physiol. 2014;4:657-89.

14. Nielsen B, Hales JR, Strange S, Christensen NJ, Warberg J, Saltin B. Human circulatory and thermoregulatory adaptations with heat acclimation and exercise in a hot, dry environment. J Physiol. 1993;460:467-85.

15. Galloway SD, Maughan RJ. Effects of ambient temperature on the capacity to perform prolonged cycle exercise in man. Med Sci Sports Exerc. 1997;29:1240-9.

16. González-Alonso J, Teller C, Andersen SL, Jensen FB, Hyldig $\mathrm{T}$, Nielsen B. Influence of body temperature on the development of fatigue during prolonged exercise in the heat. J Appl Physiol. 1999;86:1032-9.

17. González-Alonso J, Mora-Rodríguez R, Coyle EF. Stroke volume during exercise: interaction of environment and hydration. Am J Physiol Heart Circ Physiol. 2000;278:H321-30.

18. Ely BR, Cheuvront SN, Kenefick RW, Sawka MN. Aerobic performance is degraded, despite modest hyperthermia, in hot environments. Med Sci Sports Exerc. 2010;42:135-41.

19. Sawka MN, Cheuvront SN, Kenefick RW. High skin temperature and hypohydration impair aerobic performance. Exp Physiol. 2012;97:327-32.

20. MacDougall JD, Reddan WG, Layton CR, Dempsey JA. Effects of metabolic hyperthermia on performance during heavy prolonged exercise. J Appl Physiol. 1974;36:538-44.

21. Périard JD, Cramer MN, Chapman PG, Caillaud C, Thompson MW. Cardiovascular strain impairs prolonged self-paced exercise in the heat. Exp Physiol. 2011;96:134-44.

22. Lorenzo S, Halliwill JR, Sawka MN, Minson CT. Heat acclimation improves exercise performance. J Appl Physiol. 2010;109:1140-7.

23. Tatterson AJ, Hahn AG, Martini DT, Febbraio MA. Effects of heat stress on physiological responses and exercise performance in elite cyclists. J Sci Med Sport. 2000;3:186-93.

24. Sawka MN, Young AJ, Latzka WA, Neufer PD, Quigley MD, Pandolf KB, et al. Human tolerance to heat strain during exercise: influence of hydration. J Appl Physiol. 1992;73:368-75.

25. Castellani JW, Muza SR, Cheuvront SN, Sils IV, Fulco CS, Kenefick RW, et al. Effect of hypohydration and altitude exposure on aerobic exercise performance and acute mountain sickness. J Appl Physiol. 2010;109:1792-800.

26. González-Alonso J, Calbet JA, Nielsen B. Muscle blood flow is reduced with dehydration during prolonged exercise in humans. J Physiol. 1998;513:895-905.

27. Hargreaves M, Dillo P, Angus D, Febbraio M. Effect of fluid ingestion on muscle metabolism during prolonged exercise. J Appl Physiol. 1996;80:363-6.

28. Logan-Sprenger HM, Heigenhauser GJF, Killian KJ, Spriet LL. Effects of dehydration during cycling on skeletal muscle metabolism in females. Med Sci Sports Exerc. 2012;44:1949-57.

29. Logan-Sprenger HM, Heigenhauser GJF, Jones GL, Spriet LL. Increase in skeletal-muscle glycogenolysis and perceived exertion with progressive dehydration during cycling in hydrated men. Int J Sport Nutr Exerc Metab. 2013;23:220-9.

30. Jentjens RLPG, Wagenmakers AJM, Jeukendrup AE. Heat stress increases muscle glycogen use but reduces the oxidation of ingested carbohydrates during exercise. J Appl Physiol. 2002;92:1562-72.
31. Logan-Sprenger HM, Heigenhauser GJF, Jones GL, Spriet LL. The effect of dehydration on muscle metabolism and time trial performance during prolonged cycling in males. Physiol Rep. 2015;3:1-13.

32. Klausen K, Dill DB, Phillips EE Jr, McGregor D. Metabolic reactions to work in the desert. J Appl Physiol. 1967;22:292-6.

33. Pirnay F, Deroanne R, Petit JM. Maximal oxygen consumption in a hot environment. J Appl Physiol. 1970;28:642-5.

34. Nybo L, Jensen T, Nielsen B, González-Alonso J. Effects of marked hyperthermia with and without dehydration on $\dot{V} \mathrm{O}_{2}$ kinetics during intense exercise. J Appl Physiol. 2001;90:1057-64.

35. González-Alonso J, Calbet JA. Reductions in systemic and skeletal muscle blood flow and oxygen delivery limit maximal aerobic capacity in humans. Circulation. 2003;107:824-30.

36. Arngrímsson SÁ, Petitt DS, Borrani F, Skinner KA, Cureton KJ. Hyperthermia and maximal oxygen uptake in men and women. Eur J Appl Physiol. 2004;92:524-32.

37. Lafrenz AJ, Wingo JE, Ganio MS, Cureton KJ. Effect of ambient temperature on cardiovascular drift and maximal oxygen uptake. Med Sci Sports Exerc. 2008;40:1065-71.

38. Trangmar SJ, Chiesa ST, Kalsi KK, Secher NH, GonzálezAlonso J. Whole body hyperthermia, but not skin hyperthermia, accelerates brain and locomotor limb circulatory strain and impairs exercise capacity in humans. Physiol Rep. 2017;5:e13108.

39. Rowell LB, Brengelmann GL, Murray J, Kraning KK, Kusumi F. Human metabolic responses to hyperthermia during mild to maximal exercise. J Appl Physiol. 1969;26:395-402.

40. Saltin B. Aerobic and anaerobic work capacity after dehydration. J Appl Physiol. 1964;19:1114-8.

41. Buskirk ER, Iampietro PF, Bass DE. Work performance after dehydration: effects of physical conditioning and heat acclimatization. J Appl Phyiol. 1958;12:189-94.

42. Armstrong LE, Costill DL, Fink WJ. Influence of diureticinduced dehydration on competitive running performance. Med Sci Sports Exerc. 1985;17:456-61.

43. Ganio MS, Wingo JE, Carroll CE, Thomas MK, Cureton KJ. Fluid ingestion attenuates the decline in $\dot{V} \mathrm{O}_{2 \text { peak }}$ associated with cardiovascular drift. Med Sci Sports Exerc. 2006;38:901-9.

44. Sawka MN. Thermal and circulatory responses to repeated bouts of prolonged running. Med Sci Sports Exerc. 1979;11:177-80.

45. Montain SJ, Coyle EF. Influence of graded dehydration on hyperthermia and cardiovascular drift during exercise. J Appl Physiol. 1992;73:1340-50.

46. Montain SJ, Sawka MN, Latzka WA, Valeri CR. Thermal and cardiovascular strain from hypohydration: influence of exercise intensity. Int J Sports Med. 1998;19:87-91.

47. Hamilton MT, González-Alonso J, Montain SJ, Coyle EF. Fluid replacement and glucose infusion during exercise prevent cardiovascular drift. J Appl Physiol. 1991;71:871-7.

48. González-Alonso J, Mora-Rodríguez R, Below PR, Coyle EF. Dehydration reduces cardiac output and increases systemic and cutaneous vascular resistance during exercise. J Appl Physiol. 1995;79:1487-96.

49. González-Alonso J, Mora-Rodríguez R, Below PR, Coyle EF. Dehydration markedly impairs cardiovascular function in hyperthermic endurance athletes during exercise. J Appl Physiol. 1997;82:1229-36.

50. Fritzsche RG, Switzer TW, Hodgkinson BJ, Coyle EF. Stroke volume decline during prolonged exercise is influenced by the increase in heart rate. J Appl Physiol. 1999;86:799-805.

51. Crandall CG, Wilson TE, Marving J, Vogelsang TW, Kjaer A, Hesse B, et al. Effects of passive heating on central blood volume and ventricular dimensions in humans. J Physiol. 2008;586:293-301. 
52. Stöhr EJ, González-Alonso J, Pearson J, Low DA, Ali L, Barker $\mathrm{H}$, et al. Effects of graded heat stress on global left ventricular function and twist mechanics at rest and during exercise in healthy humans. Exp Physiol. 2011;96:114-24.

53. Wilson TE, Brothers RM, Tollund C, Dawson EA, Nissen P, Yoshiga CC, et al. Effect of thermal stress on Frank-Starling relations in humans. J Physiol. 2009;587:3383-92.

54. Stöhr EJ, González-Alonso J, Pearson J, Low DA, Ali L, Barker $\mathrm{H}$, et al. Dehydration reduces left ventricular filling at rest and during exercise independent of twist mechanics. J Appl Physiol. 2011;111:891-7.

55. Fehling PC, Haller JM, Lefferts WK, Hultquist EM, Wharton M, Rowland TW, et al. Effect of exercise, heat stress and dehydration on myocardial performance. Occup Med (Chic Ill). 2015;65:317-23.

56. Nottin S, Doucende G, Schuster I, Tanguy S, Dauzat M, Obert P. Alteration in left ventricular strains and torsional mechanics after ultralong duration exercise in athletes. Circ Cardiovasc Imaging. 2009;2:323-30.

57. Trinity JD, Pahnke MD, Lee JF, Coyle EF. Interaction of hyperthermia and heart rate on stroke volume during prolonged exercise. J Appl Physiol. 2010;109:745-51.

58. Chou T-H, Allen JR, Hahn D, Leary BK, Coyle EF. Cardiovascular responses to exercise when increasing skin temperature with narrowing of the core-to-skin temperature gradient. J Appl Physiol. 2018;125:697-705.

59. Coyle EF, González-Alonso J. Cardiovascular drift during prolonged exercise: new perspectives. Exerc Sport Sci Rev. 2001;29:88-92.

60. Munch GDW, Svendsen JH, Damsgaard R, Secher NH, GonzálezAlonso J, Mortensen SP. Maximal heart rate does not limit cardiovascular capacity in healthy humans: insight from right atrial pacing during maximal exercise. J Physiol. 2014;592:377-90.

61. Pearson J, Kalsi KK, Stöhr EJ, Low DA, Barker H, Ali L, et al. Haemodynamic responses to dehydration in the resting and exercising human leg. Eur J Appl Physiol. 2013;113:1499-509.

62. Nielsen B, Savard G, Richter E, Hargreaves M, Saltin B. Muscle blood flow and muscle metabolism during exercise and heat stress. J Appl Physiol. 1990;69:1040-6.

63. Søren N, Niels S, Christensen J, Nielsen B, Strange S, Christensen NJ, et al. Acute and adaptive responses in humans to exercise in a warm, humid environment. Pflugers Arch. 1997;434:49-56.

64. Mortensen SP, González-Alonso J, Damsgaard R, Saltin B, Hellsten Y. Inhibition of nitric oxide and prostaglandins, but not endothelial-derived hyperpolarizing factors, reduces blood flow and aerobic energy turnover in the exercising human leg. $\mathrm{J}$ Physiol. 2007;581:853-61.

65. Rosenmeier JB, Yegutkin GG, González-Alonso J. Activation of ATP/UTP-selective receptors increases blood flow and blunts sympathetic vasoconstriction in human skeletal muscle. J Physiol. 2008;586:4993-5002.

66. González-Alonso J, Mortensen SP, Jeppesen TD, Ali L, Barker $\mathrm{H}$, Damsgaard R, et al. Haemodynamic responses to exercise, ATP infusion and thigh compression in humans: insight into the role of muscle mechanisms on cardiovascular function. J Physiol. 2008;586:2405-17.

67. González-Alonso J, Mortensen SP, Dawson EA, Secher NH, Damsgaard R. Erythrocytes and the regulation of human skeletal muscle blood flow and oxygen delivery: role of erythrocyte count and oxygenation state of haemoglobin. J Physiol. 2006;572:295-305.

68. Pearson J, Low DA, Stöhr E, Kalsi K, Ali L, Barker H, et al. Hemodynamic responses to heat stress in the resting and exercising human leg: insight into the effect of temperature on skeletal muscle blood flow. Am J Physiol Regul Integr Comp Physiol. 2011;300:R663-73.

69. Chiesa ST, Trangmar SJ, Kalsi KK, Rakobowchuk M, Banker DS, Lotlikar MD, et al. Local temperature-sensitive mechanisms are important mediators of limb tissue hyperemia in the heat-stressed human at rest and during small muscle mass exercise. Am J Physiol Heart Circ Physiol. 2015;309:H369-80.

70. Saltin B, Rådegran G, Koskolou MD, Roach RC. Skeletal muscle blood flow in humans and its regulation during exercise. Acta Physiol Scand. 1998;162:421-36.

71. Clifford PS, Hellsten Y. Vasodilatory mechanisms in contracting skeletal muscle. J Appl Physiol. 2004;97:393-403.

72. Joyner MJ, Casey DP. Regulation of increased blood flow (hyperemia) to muscles during exercise: a hierarchy of competing physiological needs. Physiol Rev. 2015;95:549-601.

73. Chiesa ST, Trangmar SJ, González-Alonso J. Temperature and blood flow distribution in the human leg during passive heat stress. J Appl Physiol. 2016;120:1047-58.

74. Kalsi KK, Chiesa ST, Trangmar SJ, Ali L, Lotlikar MD, González-Alonso J. Mechanisms for the control of local tissue blood flow during thermal interventions: influence of temperature-dependent ATP release from human blood and endothelial cells. Exp Physiol. 2017;102:228-44.

75. Heinonen I, Brothers RM, Kemppainen J, Knuuti J, Kalliokoski KK, Crandall CG. Local heating, but not indirect whole body heating, increases human skeletal muscle blood flow. J Appl Physiol. 2011;111:818-24.

76. González-Alonso J. ATP as a mediator of erythrocyte-dependent regulation of skeletal muscle blood flow and oxygen delivery in humans. J Physiol. 2012;590:5001-13.

77. Lassen NA. Normal average value of cerebral blood flow in younger adults is $50 \mathrm{ml} / 100 \mathrm{~g} / \mathrm{min}$. J Cereb Blood Flow Metab. 1985;5:347-9.

78. Madsen PL, Holm S, Herning M, Lassen NA. Average blood flow and oxygen uptake in the human brain during resting wakefulness: a critical appraisal of the Kety-Schmidt technique. J Cereb Blood Flow Metab. 1993;13:646-55.

79. Kety SS, Schmidt CF. The nitrous oxide method for the quantitative determination of cerebral blood flow in man: theory, procedure and normal values. J Clin Invest. 1948;27:476-83.

80. Kety SS, Schmidt CF. Measurement of cerebral blood flow and cerebral oxygen consumption in man. Fed Proc. 1946;5:264.

81. Kety SS, Schmidt CF. The effects of altered arterial tensions of carbon dioxide and oxygen on cerebral blood flow and cerebral oxygen consumption of normal young men. J Clin Invest. 1948;27:484-92.

82. Scheinberg P, Blackburn I, Saslaw M, Rich M, Baum G. Cerebral circulation and metabolism in pulmonary emphysema and fibrosis with observations on the effects of mild exercise. J Clin Invest. 1953;32:720-8.

83. Scheinberg P, Blackburn LI, Rich M, Saslaw M. Effects of vigorous physical exercise on cerebral circulation and metabolism. Am J Med. 1954;16:549-54.

84. Hedlund S, Nylin G, Regnström O. The behaviour of the cerebral circulation during muscular exercise. Acta Physiol Scand. 1962;54:316-24.

85. Zobl EG, Talmers FN, Christensen RC, Baer LJ. Effect of exercise on the cerebral circulation and metabolism. J Appl Physiol. 1965;20:1289-93.

86. Ide K, Secher NH. Cerebral blood flow and metabolism during exercise. Prog Neurobiol. 2000;61:397-414.

87. Madsen PL, Sperling BK, Warming T, Schmidt JF, Secher NH, Wildschiødtz G, et al. Middle cerebral artery blood velocity and cerebral blood flow and $\mathrm{O}_{2}$ uptake during dynamic exercise. J Appl Physiol. 1993;74:245-50. 
88. Secher NH, Seifert T, Van Lieshout JJ. Cerebral blood flow and metabolism during exercise: implications for fatigue. J Appl Physiol. 2008;104:306-14.

89. Ferrier C, Jennings GL, Eisenhofer G, Lambert G, Cox HS, Kalff V, et al. Evidence for increased noradrenaline release from subcortical brain regions in essential hypertension. $\mathrm{J}$ Hypertens. 1993;11:1217-27.

90. Smith KJ, Wong LE, Eves ND, Koelwyn GJ, Smirl JD, Willie CK, et al. Regional cerebral blood flow distribution during exercise: influence of oxygen. Respir Physiol Neurobiol. 2012;184:97-105.

91. Olesen J. Contralateral focal increase of cerebral blood flow in man during arm work. Brain. 1971;94:635-46.

92. Smith KJ, Wildfong KW, Hoiland RL, Harper H, Lewis NCS, Pool A, et al. Role of $\mathrm{CO}_{2}$ in the cerebral hyperemic response to incremental normoxic and hyperoxic exercise. J Appl Physiol. 2016;120(8):843-54.

93. Pott F, Ray CA, Olesen HL, Ide K, Secher NH, Copenhagen T, et al. Middle cerebral artery blood velocity, arterial diameter and muscle sympathetic nerve activity during post-exercise muscle ischaemia. Acta Physiol Scand. 1997;160:43-7.

94. Hellstrom G, Fischer-Colbrie W, Wahlgren NG, Jogestrand T. Carotid artery blood flow and middle cerebral artery blood flow velocity during physical exercise. J Appl Physiol. 1996;81:413-8.

95. Sato K, Ogoh S, Hirasawa A, Oue A, Sadamoto T. The distribution of blood flow in the carotid and vertebral arteries during dynamic exercise in humans. J Physiol. 2011;589:2847-56.

96. Jørgensen LG, Perko M, Perko G, Secher NH. Middle cerebral artery velocity during head-up tilt induced hypovolaemic shock in humans. Clin Physiol. 1993;13:323-36.

97. Moraine JJ, Lamotte M, Berré J, Niset G, Leduc A, Naeijel R. Relationship of middle cerebral artery blood flow velocity to intensity during dynamic exercise in normal subjects. Eur J Appl Physiol Occup Physiol. 1993;67:35-8.

98. Jørgensen LG, Perko M, Hanel B, Schroeder TV, Secher NH. Middle cerebral artery flow velocity and blood flow during exercise and muscle ischemia in humans. J Appl Physiol. 1992;72:1123-32.

99. Thomas SN, Schroeder T, Secher NH, Mitchell JH. Cerebral blood flow during submaximal and maximal dynamic exercise in humans. J Appl Physiol. 1989;67:744-8.

100. Nybo L, Nielsen B. Middle cerebral artery blood velocity is reduced with hyperthermia during prolonged exercise in humans. J Physiol. 2001;534:279-86.

101. Linkis P, Jørgensen LG, Olesen HL, Madsen PL, Lassen NANA, Linkis $P$, et al. Dynamic exercise enhances regional cerebral artery mean flow velocity. J Appl Physiol. 1995;78:12-6.

102. Ogoh S, Sato K, Okazaki K, Miyamoto T, Hirasawa A, Morimoto $\mathrm{K}$, et al. Blood flow distribution during heat stress: cerebral and systemic blood flow. J Cereb Blood Flow Metab. 2013;33:1915-20.

103. Fan J-L, Cotter JD, Lucas RAI, Thomas K, Wilson L, Ainslie PN. Human cardiorespiratory and cerebrovascular function during severe passive hyperthermia: effects of mild hypohydration. $\mathbf{J}$ Appl Physiol. 2008;105:433-45.

104. Nybo L, Møller K, Volianitis S, Nielsen B, Secher NH, Moller K, et al. Effects of hyperthermia on cerebral blood flow and metabolism during prolonged exercise in humans. J Appl Physiol. 2002;93:58-64.

105. Périard JD, Racinais S. Heat stress exacerbates the reduction in middle cerebral artery blood velocity during prolonged selfpaced exercise. Scand J Med Sci Sport. 2015;25:135-44.

106. Trangmar SJ, Chiesa ST, Llodio I, Garcia B, Kalsi KK, Secher NH, et al. Dehydration accelerates reductions in cerebral blood flow during prolonged exercise in the heat without compromising brain metabolism. Am J Physiol Heart Circ Physiol. 2015;309:H1598-607.

107. González-Alonso J, Dalsgaard MK, Osada T, Volianitis S, Dawson EA, Yoshiga CC, et al. Brain and central haemodynamics and oxygenation during maximal exercise in humans. J Physiol. 2004;557:331-42.

108. Trangmar SJ, Chiesa ST, Stock CG, Kalsi KK, Secher NH, González-Alonso J. Dehydration affects cerebral blood flow but not its metabolic rate for oxygen during maximal exercise in trained humans. J Physiol. 2014;592:3143-60.

109. Willie CK, Tzeng Y-C, Fisher JA, Ainslie PN. Integrative regulation of human brain blood flow. J Physiol. 2014;592:841-59.

110. Smith KJ, Ainslie PN. Regulation of cerebral blood flow and metabolism during exercise. Exp Physiol. 2017;102:1356-71.

111. Brassard P, Tymko MM, Ainslie PN. Sympathetic control of the brain circulation: Appreciating the complexities to better understand the controversy. Auton Neurosci. 2017;207:37-47.

112. Willie CK, Macleod DB, Shaw AD, Smith KJ, Tzeng YC, Eves $\mathrm{ND}$, et al. Regional brain blood flow in man during acute changes in arterial blood gases. J Physiol. 2012;590:3261-75.

113. Bain AR, Smith KJ, Lewis NC, Foster GE, Wildfong KW, Willie $\mathrm{CK}$, et al. Regional changes in brain blood flow during severe passive hyperthermia: effects of $\mathrm{PaCO}_{2}$ and extracranial blood flow. J Appl Physiol. 2013;115:653-9.

114. Nelson MD, Haykowsky MJ, Stickland MK, Altamirano-Diaz LA, Willie CK, Smith KJ, et al. Reductions in cerebral blood flow during passive heat stress in humans: partitioning the mechanisms. J Physiol. 2011;589:4053-64.

115. Rasmussen P, Nybo L, Volianitis S, Møller K, Secher NH, Gjedde A. Cerebral oxygenation is reduced during hyperthermic exercise in humans. Acta Physiol. 2010;199:63-70.

116. Todd G, Butler JE, Taylor JL, Gandevia SC. Hyperthermia: a failure of the motor cortex and the muscle. J Physiol. 2005;563:621-31

117. Ross EZ, Cotter JD, Wilson L, Fan J-L, Lucas SJE, Ainslie PN. Cerebrovascular and corticomotor function during progressive passive hyperthermia in humans. J Appl Physiol. 2012;112:748-58.

118. Kempton MJ, Ettinger U, Foster R, Williams SCR, Calvert GA, Hampshire A, et al. Dehydration affects brain structure and function in healthy adolescents. Hum Brain Mapp. 2011;32:71-9.

119. Piil JF, Lundbye-Jensen J, Trangmar SJ, Nybo L. Performance in complex motor tasks deteriorates in hyperthermic humans. Temperature. 2017;4:1-9.

120. Ogoh S, Tsukamoto H, Hirasawa A, Hasegawa H, Hirose N, Hashimoto T. The effect of changes in cerebral blood flow on cognitive function during exercise. Physiol Rep. 2014;2:1-8.

121. Ogoh S. Relationship between cognitive function and regulation of cerebral blood flow. J Physiol Sci. 2017;67:345-51.

122. Wittbrodt MT, Sawka MN, Mizelle JC, Wheaton LA, Millard-Stafford ML. Exercise-heat stress with and without water replacement alters brain structures and impairs visuomotor performance. Physiol Rep. 2018;6:e13805.

123. Ganio MS, Armstrong LE, Casa DJ, McDermott BP, Lee EC, Yamamoto LM, et al. Mild dehydration impairs cognitive performance and mood of men. Br J Nutr. 2011;106:1535-43.

124. Cian C, Barraud PA, Melin B, Raphel C. Effects of fluid ingestion on cognitive function after heat stress or exercise-induced dehydration. Int J Psychophysiol. 2001;42:243-51.

125. Fisher JP, Hartwich D, Seifert T, Olesen ND, McNulty CL, Nielsen HB, et al. Cerebral perfusion, oxygenation and metabolism during exercise in young and elderly individuals. J Physiol. 2013;591:1859-70.

126. Smith K, Macleod D, Willie C, Lewis N, Tymko M, Macleod $\mathrm{N}$, et al. Cerebral oxidative metabolism during exhaustive 
exercise and recovery at sea level and high altitude. FASEB J. 2014;28(853):12.

127. Gisolf J, van Lieshout JJ, van Heusden K, Pott F, Stok WJ, Karemaker JM. Human cerebral venous outflow pathway depends on posture and central venous pressure. J Physiol. 2004;560:317-27.

128. González-Alonso J. Hyperthermia impairs brain, heart and muscle function in exercising humans. Sports Med. 2007;37:371-3.

129. Merry TL, Ainslie PN, Cotter JD. Effects of aerobic fitness on hypohydration-induced physiological strain and exercise impairment. Acta Physiol. 2010;198:179-90.

130. Sawka MN, Young AJ, Francesconi RP, Muza SR, Pandolf KB. Thermoregulatory and blood responses during exercise at graded hypohydration levels. J Appl Physiol. 1985;59:1394-401.

131. Nybo L, Nielsen B. Hyperthermia and central fatigue during prolonged exercise in humans. J Appl Physiol. 2001;91:1055-60.

132. Mortensen SP, Dawson EA, Yoshiga CC, Dalsgaard MK, Damsgaard R, Secher NH, et al. Limitations to systemic and locomotor limb muscle oxygen delivery and uptake during maximal exercise in humans. J Physiol. 2005;566:273-85.
133. Mortensen SP, Damsgaard R, Dawson EA, Secher NH, GonzálezAlonso J. Restrictions in systemic and locomotor skeletal muscle perfusion, oxygen supply and $\dot{V} \mathrm{O}_{2}$ during high-intensity wholebody exercise in humans. J Physiol. 2008;586:2621-35.

134. Montain SJ, Smith SA, Mattot RP, Zientara GP, Jolesz FA, Sawka MN. Hypohydration effects on skeletal muscle performance and metabolism: a 31P-MRS study. J Appl Physiol. 1998;84:1889-94.

135. Kenefick RW, Mahood NV, Hazzard MP, Quinn TJ, Castellani JW. Hypohydration effects on thermoregulation during moderate exercise in the cold. Eur J Appl Physiol. 2004;92:565-70.

136. Allen DG, Lamb GD, Westerblad H. Skeletal muscle fatigue: cellular mechanisms. Physiol Rev. 2008;88:287-332.

137. González-Alonso J, Calbet JAL, Nielsen B. Metabolic and thermodynamic responses to dehydration-induced reductions in muscle blood flow in exercising humans. J Physiol. 1999;520:577-89. 